\author{
Marquette University \\ e-Publications@Marquette
}

Physical Therapy Faculty Research and Publications

Physical Therapy, Department of

$7-2010$

\title{
A Role for the Kolliker-Fuse Nucleus in Cholinergic Modulation of Breathing at Night During Wakefulness and NREM Sleep
}

Joshua M. Bonis

Medical College of Wisconsin

Suzanne E. Neumueller

Medical College of Wisconsin

Katie L. Krause

Medical College of Wisconsin

T. Kiner

Medical College of Wisconsin

A. Smith

Medical College of Wisconsin

See next page for additional authors

Follow this and additional works at: https://epublications.marquette.edu/phys_therapy_fac

Part of the Life Sciences Commons

\section{Recommended Citation}

Bonis, Joshua M.; Neumueller, Suzanne E.; Krause, Katie L.; Kiner, T.; Smith, A.; Marshall, B. D.; Qian, B.; Pan, Lawrence; and Forster, Hubert V., "A Role for the Kolliker-Fuse Nucleus in Cholinergic Modulation of Breathing at Night During Wakefulness and NREM Sleep" (2010). Physical Therapy Faculty Research and Publications. 75.

https://epublications.marquette.edu/phys_therapy_fac/75 
Authors

Joshua M. Bonis, Suzanne E. Neumueller, Katie L. Krause, T. Kiner, A. Smith, B. D. Marshall, B. Qian, Lawrence Pan, and Hubert V. Forster

This article is available at e-Publications@Marquette: https://epublications.marquette.edu/phys_therapy_fac/75 


\title{
A Role for The Kölliker-Fuse Nucleus in Cholinergic Modulation of Breathing at Night During Wakefulness and NREM Sleep
}

\author{
J.M. Bonis \\ Department of Physiology, Medical College of Wisconsin, \\ Milwaukee, WI \\ S.E. Neumueller \\ Department of Physiology, Medical College of Wisconsin, \\ Milwaukee, WI \\ K.L. Krause \\ Department of Physiology, Medical College of Wisconsin, \\ Milwaukee, WI \\ T. Kiner \\ Department of Physiology, Medical College of Wisconsin, \\ Milwaukee, WI \\ A. Smith \\ Department of Physiology, Medical College of Wisconsin, \\ Milwaukee, WI
}

Journal of Applied Physiology, Vol 109, No. 1 (July 2010): pg. 159-170. DOI. This article is @ American Physiological Society and permission has been granted for this version to appear in e-Publications@Marquette. American Physiological Society does not grant permission for this article to be further copied/distributed or hosted elsewhere without the express permission from American Physiological Society. 
NOT THE PUBLISHED VERSION; this is the author's final, peer-reviewed manuscript. The published version may be accessed by following the link in the citation at the bottom of the page.

\author{
B.D. Marshall \\ Department of Physiology, Medical College of Wisconsin, \\ Milwaukee, WI \\ B. Qian \\ Department of Physiology, Medical College of Wisconsin, \\ Milwaukee, WI \\ L.G. Pan \\ Department of Physical Therapy, Marquette University, \\ Milwaukee, WI \\ H.V. Forster \\ Department of Physiology, Medical College of Wisconsin, \\ Veterans Affairs Medical Center, \\ Milwaukee, WI
}

\begin{abstract}
For many years, acetylcholine has been known to contribute to the control of breathing and sleep. To probe further the contributions of cholinergic rostral pontine systems in control of breathing, we designed this study to test the hypothesis that microdialysis (MD) of the muscarinic receptor antagonist atropine into the pontine respiratory group (PRG) would decrease breathing more in animals while awake than while in NREM sleep. In 16 goats, cannulas were bilaterally implanted into rostral pontine tegmental nuclei $(n=3)$, the lateral $(n=3)$ or medial $(n=4)$ parabrachial nuclei, or the Kölliker-Fuse nucleus (KFN; $n=6$ ). After $>2$ wk of recovery from surgery, the goats were studied during a 45-min period of MD with mock cerebrospinal fluid (mCSF), followed by at least $30 \mathrm{~min}$ of recovery and a second 45 -min period of MD with atropine. Unilateral and bilateral MD studies were completed during the day and at night. MD of atropine into the KFN at night decreased pulmonary ventilation and breathing frequency and increased inspiratory and expiratory time by $12-14 \%$ during both wakefulness and NREM sleep. However, during daytime studies, MD of atropine into the KFN had no effect on these variables. Unilateral and bilateral nighttime MD of atropine into the KFN increased levels of NREM sleep by 63 and 365\%, respectively. MD during the day or at night into the other three pontine sites had minimal effects on any variable studied. Finally, compared with MD of $\mathrm{mCSF}$, bilateral MD of atropine decreased levels of acetylcholine and choline in the effluent dialysis fluid. Our data support the concept that the KFN is a significant contributor to cholinergically modulated control of breathing and sleep.
\end{abstract}

Keywords: non-rapid eye movement sleep, pons

Journal of Applied Physiology, Vol 109, No. 1 (July 2010): pg. 159-170. DOI. This article is @ American Physiological Society and permission has been granted for this version to appear in e-Publications@Marquette. American Physiological Society does not grant permission for this article to be further copied/distributed or hosted elsewhere without the express permission from American Physiological Society. 
For many years, acetylcholine (ACh) has been known to play a role in the control of breathing ${ }^{14}$ and sleep. ${ }^{3}$ In the medial pontine reticular formation (MPRF), endogenous $A C h$ release causes statedependent changes in respiratory control $^{2}$ and can stimulate rapid eye movement (REM) sleep. ${ }^{22}$ Microadministration of the cholinergic agonists carbachol (mixed cholinergic agonist), bethanechol (muscarinic agonist), and neostigmine (acetylcholine esterase inhibitor) into the mPRF are all known to generate this effect, $1,2,18,22,27$ whereas the muscarinic antagonist atropine can block this effect. ${ }^{1}$ Indeed, mPRF cholinoceptive mechanisms can cause state-dependent changes in the firing rates of respiratory neurons in the parabrachial nuclei. ${ }^{16}$ These studies provide evidence of anatomic connectivity from the MPRF to the pontine respiratory group (PRG). Evidence of projections in the reverse direction, from the PRG to the MPRF, is provided by microinjection of fluorescent dyes into the PRG, resulting in ipsi- and contralateral positive regions in the MPRF as well as in the dorsal respiratory group and ventral respiratory group in the medulla. ${ }^{20}$ However, studies of the connectivity between brain stem respiratory neurons performed using chronically implanted arrays of microelectrodes emphasized "a sparse distribution of functional connections," which suggests that interactions between brain stem neurons include less direct pathways. ${ }^{29,32}$

Through interactions between brain stem respiratory neurons, PRG neurons contribute not only to respiratory phase switching7,10,11,36 but also to multiple aspects of ventilatory control, including a postulated critical role in dampening respiratory instabilities during sleep. ${ }^{7,14,16,20,24}$ Many of the concepts regarding the role of cholinergic modulation of breathing during sleep are based on studies during REM sleep induced by cholinergic mimetics. These studies have led to the hypothesis that "central cholinergic neurotransmission in reticular regions known to generate REM sleep can contribute to statedependent respiratory depression".22 However, there have been relatively few studies on the contribution of cholinergic modulation to the changes in breathing and respiratory muscle activity between wakefulness and NREM sleep. Accordingly, the primary aim of the present study was to determine the effects on breathing and respiratory muscle activity during wakefulness and spontaneous NREM sleep of reverse microdialysis (MD) of atropine into PRG subnuclei. PRG neuronal activity is lower during NREM sleep than during and permission has been granted for this version to appear in e-Publications@Marquette. American Physiological Society does not grant permission for this article to be further copied/distributed or hosted elsewhere without the express permission from American Physiological Society. 
wakefulness, ${ }^{16,30,33}$ and since this change could be due to reduced mPRF cholinergic modulation during NREM sleep, we reasoned that muscarinic receptor activity in the PRG would be greater during wakefulness than during NREM sleep. The major effect of ACh receptor activation is excitation of respiratory neurons; $;, 6,34$ thus the administration of the ACh antagonist atropine should decrease excitation more during wakefulness than during NREM sleep. Accordingly, we hypothesized that MD of atropine into the PRG would depress breathing more during wakefulness than during NREM sleep.

\section{Methods}

For our studies, we used adult goats because their large size permitted chronic implantation of stainless steel cannulas into the brain stem, enabling MD of target sites. Furthermore, the status of ventilatory parameters in goats has been well documented in our laboratory from previous studies in the medulla and cerebellum. Physiological data were acquired from 16 female adult goats weighing $46.4 \pm 1.9 \mathrm{~kg}$. Six additional goats were used for histological purposes only $(44.1 \pm 2.9 \mathrm{~kg})$. Goats were housed and studied in an environmental chamber with a fixed ambient temperature and photoperiod. All goats were allowed free access to hay and water, except during periods of study, for which they were trained to stand comfortably in a stanchion. All aspects of the study were reviewed and approved by the Medical College of Wisconsin Animal Care Committee before the studies were initiated.

\section{Surgical procedures.}

Animals were anesthetized with a mixture of ketamine and xylazine (15 and $1.25 \mathrm{mg} / \mathrm{kg}$, respectively), intubated, and mechanically ventilated with $2.5 \%$ isoflurane in $100 \%$ oxygen. All surgeries were performed under sterile conditions. A preparatory surgery was first performed in which a $5-\mathrm{cm}$ segment of each carotid artery was isolated from the vagus and elevated subcutaneously to facilitate future placement of chronic catheters for sampling and monitoring. Bipolar electromyographic (EMG) electrodes were implanted into the genioglossus, thyroid arytenoid, posterior cricoarytenoid, and thyropharyngeus muscles through an anterior 
midline incision in the neck and were exteriorized through the skin. EMG electrodes were also implanted in duplicate into both the diaphragm and abdominal muscles. These EMG electrodes allowed recording of upper airway and pump muscles activities for assessment of respiratory rhythm and pattern as well as for detection of swallows. For monitoring and scoring of sleep state, electroencephalographic (EEG) and electrooculographic (EOG) electrodes were implanted in the midline cranium and superior orbital ridge, respectively. Ceftiofur sodium (Naxcel; $4 \mathrm{mg} / \mathrm{kg} \mathrm{im}$ ) was administered once daily (QD) for 1 wk postoperatively to minimize infection. Buprenorphine hydrochloride (Buprenex; $0.005 \mathrm{mg} / \mathrm{kg} \mathrm{im}$ ) was administered twice daily (BID) for 2 days to mitigate pain.

After $\geq 3 \mathrm{wk}$, a second surgery was performed to chronically implant stainless steel unilateral or bilateral cannulas $(70-\mathrm{mm}$ length, 1.27-mm outer diameter, 0.84-mm inner diameter) into multiple sites within the rostral pons. On full recovery, the cannulas were used for focal microadministration of atropine to target brain areas. An occipital craniotomy was created through a posterior midline incision, and the dura mater was excised to expose the posterior cerebellum and medulla for visualization of obex. To standardize stereotaxic coordinates, the orientation of the dorsal medullary surface, obex, and midline were used to determine the dorsoventral, rostrocaudal, and mediolateral planes, respectively. In our first few animals, cannulas were implanted perpendicular to the brain stem, rostral to the transverse sinuses, lateral to the superior sagittal sinus, and through the rostral cerebellum. The tip of the cannula in these animals was rostral to the PRG in pontine tegmental nuclei, but these animals were useful in providing anatomical controls to our PRG-implanted animals. To target the PRG in general and to target specific subnuclei within the PRG, an "angled" approach was adopted. Cannulas were inserted caudal to the confluences of sinuses, through the midcerebellum, at angles of $10.5-24^{\circ}$ from normal (relative to the dorsal medullary surface), depending on the desired rostrocaudal coordinates. Given the subnucleus of choice, cannula implantation coordinates were adjusted within a range of coordinates: 0-2 $\mathrm{mm}$ ventral, 4-5 $\mathrm{mm}$ lateral, and 20-24 mm rostral to respective reference points. Using different coordinates in this way, we implanted cannulas at different sites within the PRG in 13 individual animals. After placement, cannulas were and permission has been granted for this version to appear in e-Publications@Marquette. American Physiological Society does not grant permission for this article to be further copied/distributed or hosted elsewhere without the express permission from American Physiological Society. 
anchored to the surrounding bone using screws and dental acrylic, and a stainless steel stylet was inserted to maintain patency.

Experienced laboratory personnel continuously monitored the goats (for at least $24 \mathrm{~h}$ ) after brain surgery until stable conditions were achieved. Buprenorphine was administered for pain as previously explained. Chloroamphenicol ( $20 \mathrm{mg} / \mathrm{kg}$ iv) was administered three times daily (TID) for 3 days to minimize infection, as was dexamethasone $(0.4 \mathrm{mg} / \mathrm{kg}$ decreasing to $0.05 \mathrm{mg} / \mathrm{kg}$ iv, TID) for 7 days to minimize swelling. Thereafter, until death, centiofur sodium and gentamycin (Gentamax 100; $6 \mathrm{mg} / \mathrm{kg}$ im, QD) were administered.

\section{Physiological measurements.}

Studies commenced $\geq 2$ wk after the brain surgery. For all studies, a custom-fitted mask was secured to the goat's muzzle, with a two-way breathing valve attached to the mask. A pneumotach was attached in series with the inspiratory side to measure flow via a Windaq computer data acquisition system. A spirometer was connected to the expiratory side, allowing determination of expired volume and concentrations of $\mathrm{CO}_{2}$ and $\mathrm{O}_{2}$ to calculate metabolic rate. $\mathrm{A}$ chronically placed catheter in the elevated carotid artery was used to continuously record arterial blood pressure and heart rate and for collection of blood samples to obtain arterial $\mathrm{pH}\left(\mathrm{pH}_{\mathrm{a}}\right), \mathrm{PcO}_{2}\left(\mathrm{PacO}_{2}\right)$, and $\mathrm{PO}_{2}$ values $\left(\mathrm{Pa}_{2}\right)$. Body temperature was measured rectally at regular intervals.

\section{In vivo microdialysis.}

The MD probes (CMA Microdialysis, Solna, Sweden) were $72 \mathrm{~mm}$ (70-mm shaft and 2-mm membrane) in total length and were inserted through the stainless steel cannula such that only the membrane (0.5$\mathrm{mm}$ diameter, 20-kDa molecular mass cutoff) penetrated the brain tissue. The probes were secured in place before the study began and remained there for the duration of the protocol. The dialysate was mock cerebrospinal fluid (mCSF: $124 \mathrm{mM} \mathrm{NaCl}, 2.0 \mathrm{mM} \mathrm{KCl}, 2.0 \mathrm{mM}$ $\mathrm{MgCl}_{2}, 1.3 \mathrm{mM} \mathrm{K}_{2} \mathrm{PO}_{4}, 2.0 \mathrm{mM} \mathrm{CaCl}$, $11 \mathrm{mM}$ glucose, and $26 \mathrm{mM}$ $\mathrm{NaHCO}_{3}$ in sterile distilled $\mathrm{H}_{2} \mathrm{O}$ ) with or without atropine. In a tonometer, this solution was heated to $39^{\circ} \mathrm{C}$ and equilibrated with a 
physiological gas mixture $\left(6.4 \% \mathrm{CO}_{2}-21 \% \mathrm{O}_{2}\right.$-balance $\left.\mathrm{N}_{2}\right)$. MD probes were double-barreled, allowing delivery and, in a subset, collection of the dialysate. Affluent dialysate was delivered (50 $\mu \mathrm{l} / \mathrm{min})$ using a syringe pump, and in a subset, effluent dialysate was collected in modified Eppendorf tubes for subsequent content analysis using liquid chromatography-electrochemistry (LC-EC). The syringes containing mCSF or atropine were connected to the MD probes by $150 \mathrm{~cm}$ of polypropylene microtubing, allowing isolation of the animal away from the syringe pump and associated activities.

The study protocol consisted of a 30-min control period followed by a $45-\mathrm{min}$ period of $\mathrm{MD}(50 \mu \mathrm{l} / \mathrm{min})$ with $\mathrm{mCSF}$, a 30-min recovery period, a second $45-\mathrm{min}$ period of MD with atropine ( $50 \mathrm{mM}$ in $\mathrm{mCSF}$ ), and, finally, another 30 min of recovery. The atropine concentration, flow rate, and dialysis period of $45 \mathrm{~min}$ were chosen because in in vitro studies, these parameters were sufficient for delivery of atropine across the membrane of the probe (Table 1 ). The duration of the recovery period was chosen because in initial studies, any effects of MD had usually been alleviated by 30 min after MD was terminated. Thus total study duration was $\geq 3 \mathrm{~h}$. Of note, the first 7-8 min of the second period of MD with atropine actually included delivery of the mCSF, which remained in the polypropylene microtubing from the first MD period. Thus any effects observed within the first 7-8 $\mathrm{min}$ of the second MD period could not be due to atropine. Arterial blood was sampled over the last 5 min of control, MD, and recovery periods and analyzed for $\mathrm{Pa}_{\mathrm{O} 2}$ (Torr), $\mathrm{Pa}_{\mathrm{CO} 2}$ (Torr), and $\mathrm{pH}_{\mathrm{a}}$ ( $\mathrm{pH}$ units) (model 248; Bayer Diagnostics).

Table 1. Differences in ACh and choline concentrations in response to microdialysis of mCSF and atropine in KFN, MPBN, and LPBN

Difference in Concentration, $\mu \mathrm{M} / \mathrm{ml}$

\begin{tabular}{lccccc} 
& \multicolumn{3}{c}{ ACh } & \multicolumn{2}{c}{ Choline } \\
\cline { 2 - 3 } \cline { 5 - 5 } Mean \pm SE & Unilateral & Bilateral & & Unilateral & Bilateral \\
$t$-test $P$ value & $0.18 \pm 0.17$ & $-0.63 \pm 0.20$ & & $0.01 \pm 0.11$ & $-0.43 \pm 0.19$ \\
KFN & 0.929 & 0.027 & & 0.936 & 0.053 \\
& -0.12 & -1.3 & & -0.28 & -0.04 \\
& -0.25 & -0.53 & & -0.16 & -0.09 \\
& +0.37 & -0.08 & & -0.28 & $\mathbf{+ 0 . 1 2}$ \\
& $\mathbf{- 0 . 1 5}$ & +0.05 & & +0.81 & $\mathbf{- 0 . 0 6}$
\end{tabular}

Journal of Applied Physiology, Vol 109, No. 1 (July 2010): pg. 159-170. DOI. This article is @ American Physiological Society and permission has been granted for this version to appear in e-Publications@Marquette. American Physiological Society does not grant permission for this article to be further copied/distributed or hosted elsewhere without the express permission from American Physiological Society. 
NOT THE PUBLISHED VERSION; this is the author's final, peer-reviewed manuscript. The published version may be accessed by following the link in the citation at the bottom of the page.

Difference in Concentration, $\mu \mathrm{M} / \mathrm{ml}$

\begin{tabular}{|c|c|c|c|c|}
\hline & \multicolumn{2}{|c|}{ ACh } & \multicolumn{2}{|c|}{ Choline } \\
\hline & Unilateral & Bilateral & $\begin{array}{c}\text { Unilateral } \\
\begin{array}{c}-0.09 \\
-0.05 \\
0 \\
-\mathbf{0 . 1 9} \\
-\mathbf{0 . 1 7} \\
\mathbf{- 0 . 7 3}\end{array}\end{array}$ & Bilateral \\
\hline \multirow[t]{8}{*}{ MPBN } & -0.21 & -1.22 & -0.11 & -1.18 \\
\hline & +0.11 & -0.1 & -0.06 & -0.31 \\
\hline & +0.04 & -2.26 & -0.47 & -0.17 \\
\hline & -0.03 & -0.25 & -0.27 & -0.04 \\
\hline & -0.35 & & -0.31 & -2.24 \\
\hline & & & 0.00 & -0.06 \\
\hline & & & 0.00 & \\
\hline & & & -0.62 & \\
\hline \multirow[t]{3}{*}{ LPBN } & +1.14 & -0.01 & +1.36 & -0.04 \\
\hline & +1.07 & -0.59 & +1.35 & -1.09 \\
\hline & +0.02 & -0.62 & +0.01 & -0.44 \\
\hline
\end{tabular}

Compared with bilateral microdialysis (MD) of mock cerebral spinal fluid (mCSF), bilateral MD of atropine significantly $(P<0.05)$ decreased the concentrations of both ACh and choline in the effluent dialysis fluid. Unilateral MD of atropine did not significantly $(P>0.05)$ affect ACh or choline concentration in the effluent dialysis fluid. Each value (mean $\pm \mathrm{SE}$ ) is the difference in concentration of ACh or choline between MD of MCSF and atropine. Data were obtained during MD into the Kölliker-Fuse nucleus (KFN) and the lateral (LPBN) and medial parabrachial nuclei (MPBN). Values in bold type were obtained from studies at night, and the remainder were obtained from studies during the day. We were unable to obtain separate values at night for awake and non-rapid eye movement (NREM) sleep states.

MD studies were conducted on six separate days, three during the day (9:00 AM to noon) and three during the night (10:00 PM to 1:00 AM). The studies at night directly tested the hypothesis regarding a state-dependent role of pontine cholinergic modulation of breathing. The studies during the day provide information on whether pontine cholinergic modulation is a determinant of breathing while goats are awake during the day and to explore possible circadian influences on the cholinergic system. Studies were never completed on consecutive days, and studies were separated by at least $36 \mathrm{~h}$. The six MD studies consisted of four unilateral studies (left and right cannulas during the day and night) and two bilateral studies (bilateral cannulas during the day and night). The sequence of the four unilateral studies was randomly determined, as was the sequence of the two bilateral 
studies. Because we were unsure whether there would be a carryover effect of atropine or an effect of inserting the dialysis probe, the unilateral studies were always completed before the bilateral studies; thus, at each unilateral site, the data obtained were not complicated by previous dialysis. For daytime studies, animals were loosely tied in a stanchion so that they could not assume sternal recumbency, which is the preferred sleep posture for goats. For studies conducted at night, goats were not allowed to assume sternal recumbency between 4:00 PM and 10:00 PM in an effort to consolidate sleep. However, goats were still permitted free access to food and water during this time. At 10:00 PM, when the nighttime study commenced, ties were removed so that the goat could assume sternal recumbency within the stanchion. All connections to the animal were adjusted to accommodate this increased range of motion.

\section{In vitro microdialysis.}

To confirm delivery of atropine across the MD probe membrane, an Eppendorf tube (reservoir) was filled with either 0.6 or $1.5 \mu \mathrm{l}$ of mCSF. A stainless steel cannula was passed through a hole bored in the reservoir cap. A MD probe was inserted through the cannula into the reservoir, and all connections were sealed with silicon gel. Atropine (50 $\mathrm{mM}$ ) in mCSF was dialyzed for $45 \mathrm{~min}$. Subsequently, the reservoir atropine concentration was determined using liquid chromatographymass spectrometry (LC-MS).

\section{Data and statistical analyses.}

Pulmonary ventilation (Vi; l/min), breathing frequency (f; breaths/min), tidal volume (Vt; I/min), expiratory (Te; s) and inspiratory times ( $\mathrm{Ti}, \mathrm{s})$, respiratory muscle activity $(\mathrm{mV})$, and, in addition for night studies, EEG and EOG activities were analyzed on a breath-by-breath basis. First, the blood pressure and airflow signals were calibrated against known values, whereas EMG signals were zeroed at the baseline. The calibrated signals were rectified and time averaged. During the experimental control periods, these rectified and time-averaged signals were used to recalibrate the EMG signals with the assignment of arbitrary peak (1) and baseline values (0). These recalibrated EMG signals were again rectified and time averaged. This 
recalibration and further processing of the EMG signals was necessary because of the absence of known values and provided a measure of relative magnitude within studies. Finally, the signals were converted to a .txt file and input into a custom-designed program that output all parameters on a breath-by-breath basis.

The EEG and EOG activities were used to visually distinguish between states of consciousness. Wakefulness was characterized by a high-frequency, low-voltage EEG, with variable EOG activity. Non-rapid eye movement (NREM) sleep was characterized by a low-frequency $(<2 \mathrm{~Hz})$, high-voltage (2-3 times greater than that found in wakefulness) EEG, with absent EOG activity. REM sleep was characterized by a high-frequency, low-voltage EEG, similar to wakefulness but concurrent with frequent and distinct bursting activity $(>30 \mu \mathrm{V})$ in the EOG. For night studies, each breath was categorized as awake, NREM sleep, or REM sleep. The breaths were then further categorized as "quiet," regular breaths or those that were "irregular/disrupted," characterized by any respiratory muscle activity that was inappropriate, including swallowing, coughing, mastication, and eructation, as well as any abnormal patterns that could not be identified as a specific behavior. The rationale for this second categorization was as stated by Bolser et al.: 8 "the presence of elements that are normally silent in close proximity to spontaneously active respiratory neurons raises the possibility that some interventions that are intended to study the neurogenesis of breathing might instead be influencing components of the holarchical system that are only conditionally active;" thus it was essential to make a delineation between the two types of breaths (nondisrupted vs. disrupted). The data reported are for periods of nondisrupted breathing.

Breath-by-breath values were averaged into 15-min bins and expressed in either their raw form or as a percentage of the bins in the control period. The 15-min bin values for the two unilateral studies on each goat were averaged, and statistical analyses of the unilateral data were performed using the averaged values. One-way analysis of variance (ANOVA) was used on all ventilatory variables for control periods to determine whether there were chronic changes as a result of cannula implantation and/or the series of MD studies. Tukey's post hoc test was used to identify specific changes. To test whether the and permission has been granted for this version to appear in e-Publications@Marquette. American Physiological Society does not grant permission for this article to be further copied/distributed or hosted elsewhere without the express permission from American Physiological Society. 
measured variables (expressed as a percentage of control) changed over the 180 min of the MD protocol and whether there were differences between goats with different sites of cannula implantation, a two-way ANOVA (time and site as factors) was used. If the ANOVA was significant, then Tukey's post hoc analysis was used to determine which values during dialysis and recovery differed from the control period. This analysis was completed for MD studies while goats were awake during the day and also for MD studies at night during the awake and NREM sleep states. These analyses were performed for both the unilateral and bilateral data.

The breath-to-breath coefficient of variation (CV) (SD/mean $x$ 100) was also calculated for each 15 -min bin for all ventilatory variables, and ANOVA and Tukey's test were used to establish statistical significance. For night studies, respective states are reported as a percentage of the total time per 15-min bin, and ANOVA and Tukey's test were used to determine whether the percentage of time in NREM sleep changed over the $180 \mathrm{~min}$ and whether there were differences between the groups. There was insufficient data during REM sleep for statistical analysis. The number of apneas (apnea Te $\geq$ $2.5 \times$ average Te) and augmented breaths (augmented breath $\mathrm{Vt} \geq$ $2.5 \times$ average $\mathrm{Vt}$ ) were tabulated for each 15-min bin. Apneas following augmented breaths were not included in the apnea analyses. ANOVA and Tukey's test were used to determine whether the number of apneas and augmented breaths changed over the 180-min protocol and whether there were group differences. To test whether levels of ACh and choline were significantly $(P<0.05)$ different between mCSF and atropine MD, a paired $t$-test was performed on effluent dialysate LC-EC raw values.

\section{Histological analyses.}

After completion of this experimental protocol, in all but one goat, we injected ibotenic acid (IA) into the PRG to determine the ventilatory effects of neurotoxic lesions (data not reported). One week after the last IA injection, the goats were euthanized (Beuthansia; intravenously), and the brain was perfused with physiological buffer solution (PBS) and fixed with 4\% paraformaldehyde (PFA) in PBS. The brain stem was excised and placed in 4\% PFA in PBS for $24 \mathrm{~h}$ and then 
in 20 and $30 \%$ sucrose solutions, sequentially. The brain stem was frozen and serially sectioned $(25 \mu \mathrm{m})$ from obex to the superior colliculi in a transverse $(n=21)$ or sagittal $(n=1)$ plane, and the sections were adhered to gelatin-chrome-alum-coated slides. Sections were acquired such that every fourth section was contained within a respective "series." Thus there were four series in total; within a series, each section was $100 \mu \mathrm{m}$ from the next section in sequence, allowing for high-resolution neuronal and anatomical profiling. One series was stained for Nissl substance to profile the total number of neurons. A second series was stained for muscarinic type-2 (M2) immunoreactivity by complexing anti-M2 receptor primary antibody (Millipore; 1:200 dilution) with biotinylated anti-mouse secondary antibody (Vector; 1:100 dilution). After the antibody-antigen complex was incubated, it was localized by avidin (Vector ABC Elite) and developed with diaminobenzene. The three PRG nuclei heavily stain for the $M 2$ receptor in contrast to an absence of staining in the superior cerebellar peduncle; thus this series was used to identify the area of the lateral (LPBN) and medial parabrachial nuclei (MPBN) and KFN. The third and fourth sections in each series were used for purposes unrelated to this report.

Since the $2 \mathrm{~mm}$ of the MD probe membrane were inserted $2 \mathrm{~mm}$ beyond the tip of the cannula, the major effect of MD would be on neurons $2 \mathrm{~mm}$ distal to the tract created by the cannula. Thus the goats were grouped according to identification of the distal end of the cannula tract visualized on the Nissl- and M2-stained sections. Accordingly, there were three, four, six, and three goats in the LPBN, MPBN, KFN, and rostral pontine tegmental nuclei (RPTN) groups, respectively.

The Nissl- and M2-stained sections in the control goats were used to establish the morphology of the LPBN, MPBN, and KFN. The nuclei were identified as described above, and then the Nissl-stained sections were used to manually count the total number of neurons and determine the area of each subnucleus (Metamorph software and standardized procedures). 
NOT THE PUBLISHED VERSION; this is the author's final, peer-reviewed manuscript. The published version may be accessed by following the link in the citation at the bottom of the page.

\section{Results}

\section{Histology and cannula placement.}

Figure $1, A$ and $B$, shows Nissl-stained sagittal and transverse sections as well as sections immunostained for the $\mathrm{M} 2$ receptor. The extensive M2 staining is consistent with a potential role of cholinergic modulation in the role of the rostral pons in the control of breathing. ${ }^{25}$ As shown by these sections and the schematic in Fig. $1 B$, the LPBN and MPBN flank the superior cerebellar peduncle (SCP), and the KFN extends ventral and lateral to the LPBN and MPBN. As shown in Fig. 2, $A$ and $B$, in goats, the morphology of the LPBN and MPBN is quite different from that of the KFN. The KFN is quite confined, spanning only 2-3 $\mathrm{mm}$ rostrocaudally, whereas the LPBN and MPBN are more widespread, spanning a rostrocaudal distance of $6-8 \mathrm{~mm}$, and are thus larger areas and include more neurons than the KFN (Fig. 2B). Accordingly, we presume that MD of atropine in the KFN likely attenuated muscarinic activity of a larger percentage of total KFN neurons than when atropine was MD in the LPBN and MPBN.

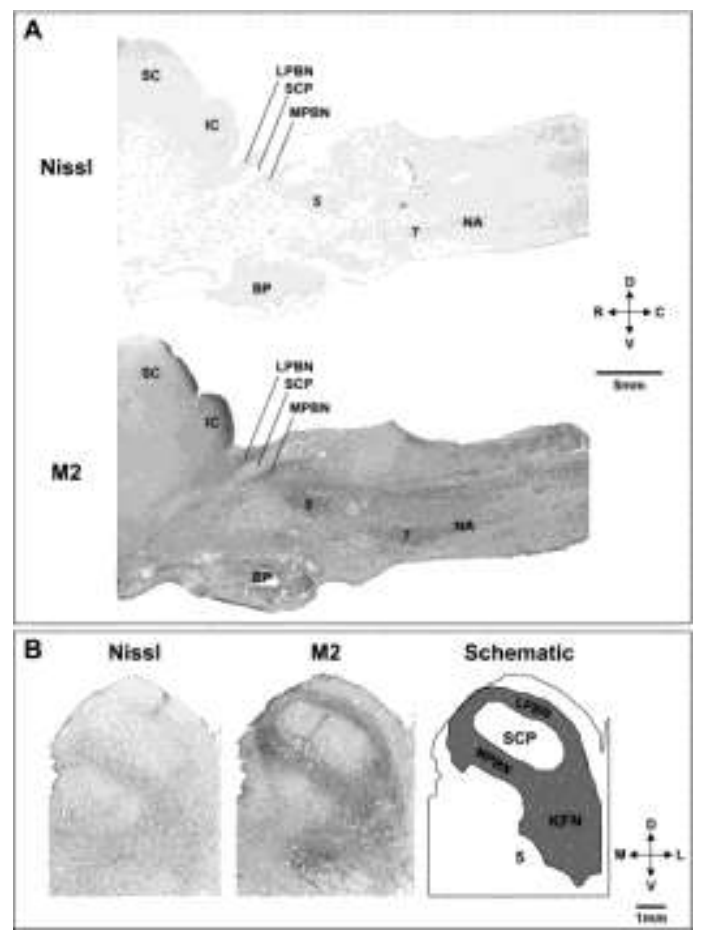

Fig. 1. Histochemical and immunohistochemical staining for Nissl substance and muscarinic type-2 (M2) receptors provides anatomic characterization of the pontine respiratory group in goats. A: sagittal sections (from a control goat) $4.9 \mathrm{~mm}$ lateral to

Journal of Applied Physiology, Vol 109, No. 1 (July 2010): pg. 159-170. DOI. This article is @ American Physiological Society and permission has been granted for this version to appear in e-Publications@Marquette. American Physiological Society does not grant permission for this article to be further copied/distributed or hosted elsewhere without the express permission from American Physiological Society. 
NOT THE PUBLISHED VERSION; this is the author's final, peer-reviewed manuscript. The published version may be accessed by following the link in the citation at the bottom of the page.

the midline show the location in the rostral, dorsal pons of the lateral (LPBN) and medial parabrachial nuclei (MPBN) and the Kölliker-Fuse nucleus (KFN) relative to the cerebellar peduncle (SCP). B: transverse Nissl- and M2-stained sections from another control goat and a schematic to further illustrate the location of the LPBN, MPBN, and KFN. The superior and inferior colliculus (IC), trigeminal motor nucleus, ${ }^{5}$ basal pons $(B P)$, facial nucleus, ${ }^{7}$ and nucleus ambiguus (NA) are labeled for reference. $D$, dorsal; $\mathrm{V}$, ventral; $\mathrm{R}$, rostral; $\mathrm{C}$, caudal; $\mathrm{M}$, medial; L, lateral.

A

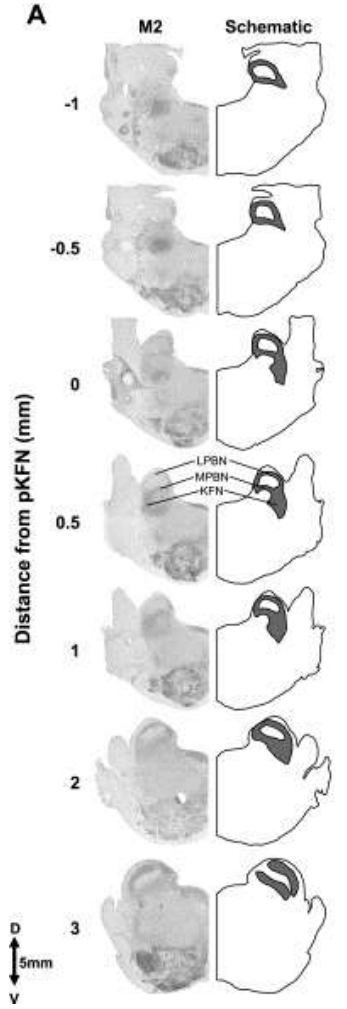

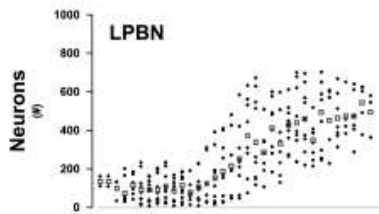
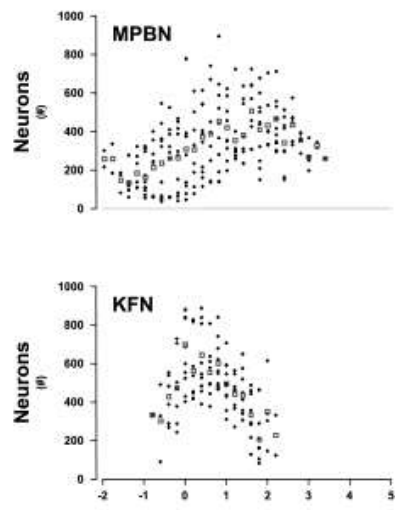

Rostrocaudal distance from pKFN

Fig. 2. In the rostrocaudal direction of control goats, there are changes in the anatomy of the LPBN, MPBN, and KFN. A: immunohistochemically stained hemisections for the $\mathrm{M} 2$ receptors of a control goat and a schematic illustrating the location of the LPBN, MPBN, and KFN at 7 different rostrocaudal distances from the peak (pKFN) number of neurons in the KFN. B: plots of the number of neurons in the LPBN, MPBN, and KFN of control goats at different rostrocaudal distances relative to the pKFN. Among the 3 subnuclei, note the differences in number of neurons rostrocaudally. Filled symbols indicate unilateral neuron counts from individual goats; open symbols indicate the mean of all control goats.

\section{Verification of MD efficacy.}

In vitro dialysis confirmed that atropine moved across the probe membrane. The concentration of atropine in the mCSF within the reservoir was 76 and $97 \mu \mathrm{M}$ for reservoir volumes of 1,500 and $600 \mu \mathrm{l}$, respectively. 
We did not measure atropine in PRG tissue during in vivo MD, but indirect evidence of a significant movement of atropine into the tissue was provided by the finding that bilateral MD of atropine decreased ACh and choline levels in the MD effluent fluid. Limited data were obtained for each PRG site, but in three of four KFN sites, four of four MPBN sites, and three of three LPBN sites, there was less ACh in the effluent sample after MD of atropine than after MD of MCSF (Table 1). The same consistent decrease was found in effluent choline concentration. Pooling the data yielded a mean difference for ACh of $-0.63 \pm 0.2 \mu \mathrm{M} / \mathrm{ml}(P<0.027)$ and for choline of $-0.043 \pm 0.19$ $\mu \mathrm{M} / \mathrm{ml}(P<0.053)$. During unilateral MD, there was no significant difference in either ACh or choline concentration between mCSF and atropine MD (Table 1).

\section{Breathing.}

Vi was significantly $(P<0.05)$ reduced 2 wk after implantation of the cannulas compared with preimplantation studies (Table 2 ). These decreases were due primarily to a reduction in Vt (Table 2) and were secondary to a reduction in metabolic rate (data not shown). Breathing frequency and arterial blood gases were not altered by implanting the cannulas (Table 2 ). There were no significant ( $P<$ $0.05)$ changes in any ventilatory variable between the control periods before the MD studies were initiated and a control period after the final MD study; thus there was no apparent chronic effect of atropine MD on eupneic breathing.

Table 2. Effects of cannula placement on physiological parameters

\section{Vi, I/min f, breaths/min Vt, I/breath Paco2, Torr Pao2, Torr} RPTN

$\begin{array}{lccccc}\text { Preimplant } & 7.60 \pm 0.98 & 20.68 \pm 2.83 & 0.40 \pm 0.02 & 39.1 \pm 1.0 & 97 \pm 5 \\ \text { Postimplant } & 6.47 \pm 0.67^{*} & 19.46 \pm 2.06 & 0.38 \pm 0.03^{*} & 39.8 \pm 1.6 & 91 \pm 6 \\ \text { Post-Atr MD } & 6.48 \pm 0.23^{*} & 21.34 \pm 1.98 & 0.36 \pm 0.02^{*} & 40.1 \pm 1.7 & 97 \pm 5 \\ & & & & & \\ \text { Preimplant } & 8.59 \pm 1.25 & 16.56 \pm 0.60 & 0.53 \pm 0.07 & 39.6 \pm 0.4 & 104 \pm 11 \\ \text { Postimplant } & 6.76 \pm 1.18^{*} & 19.77 \pm 1.60 & 0.38 \pm 0.07^{*} & 40.3 \pm 1.5 & 92 \pm 11 \\ \text { Post-Atr MD } & 6.67 \pm 0.30^{*} & 17.85 \pm 1.72 & 0.42 \pm 0.04^{*} & 41.3 \pm 0.7 & 97 \pm 3 \\ & & & & & \\ \text { Preimplant } & 6.27 \pm 0.43 & 16.47 \pm 0.90 & 0.40 \pm 0.04 & 41.6 \pm 0.7 & 101 \pm 4 \\ \text { Postimplant } & 6.39 \pm 0.60 & 18.63 \pm 1.46 & 0.35 \pm 0.02^{*} & 43.1 \pm 1.8 & 92 \pm 6 \\ \text { Post-Atr MD } & 6.31 \pm 0.58 & 19.11 \pm 0.98 & 0.34 \pm 0.02^{*} & 43.8 \pm 1.8 & 102 \pm 6\end{array}$

KFN

Journal of Applied Physiology, Vol 109, No. 1 (July 2010): pg. 159-170. DOI. This article is @ American Physiological Society and permission has been granted for this version to appear in e-Publications@Marquette. American Physiological Society does not grant permission for this article to be further copied/distributed or hosted elsewhere without the express permission from American Physiological Society. 
NOT THE PUBLISHED VERSION; this is the author's final, peer-reviewed manuscript. The published version may be accessed by following the link in the citation at the bottom of the page.

$\begin{array}{lccccc} & \mathbf{V i}, \mathbf{I} / \mathbf{m i n} & \mathbf{f}, \mathbf{b r e a t h s} / \mathbf{m i n} & \mathbf{V t} \text {, I/breath } & \text { Paco2, Torr } & \text { Pao2, Torr } \\ \text { Preimplant } & 7.79 \pm 0.78 & 17.84 \pm 1.16 & 0.46 \pm 0.04 & 41.2 \pm 0.7 & 97 \pm 4 \\ \text { Postimplant } & 6.77 \pm 0.30^{*} & 17.93 \pm 1.06 & 0.40 \pm 0.02^{*} & 39.7 \pm 0.4 & 92 \pm 2 \\ \text { Post-Atr MD } & 6.85 \pm 0.36^{*} & 16.16 \pm 1.23 & 0.47 \pm 0.04 & 39.9 \pm 0.6 & 101 \pm 3\end{array}$

After implantation of the cannula, pulmonary ventilation (Vi) was significantly reduced from preimplantation studies, and these effects were generally due to a reduction in tidal volume $(\mathrm{Vt})$.

${ }^{*} P<0.05$, significant differences from preimplantation studies. Breathing frequency (f) and arterial blood gases ( $\left.\mathrm{Pa}_{\mathrm{CO} 2}, \mathrm{PaO}_{2}\right)$ were not significantly $(P>0.05)$ changed by implantation of the cannula.

As shown in Fig. 3 for four different individual goats, during MD into three of the four rostral pontine sites, Vi was stable throughout the $3 \mathrm{~h}$ of the daytime and nighttime studies. Indeed, neither unilateral nor bilateral MD of either MCSF or atropine during daytime studies significantly $(P<0.05)$ affected $\mathrm{Vi}, \mathrm{f}, \mathrm{Ti}$, or $\mathrm{Vi}$ regardless of cannula site (Fig. 4). However, in goats with unilateral daytime MD of atropine into the LPBN, Te was increased $(P<0.05)$ by $19 \%$ during the recovery period (Fig. 3).
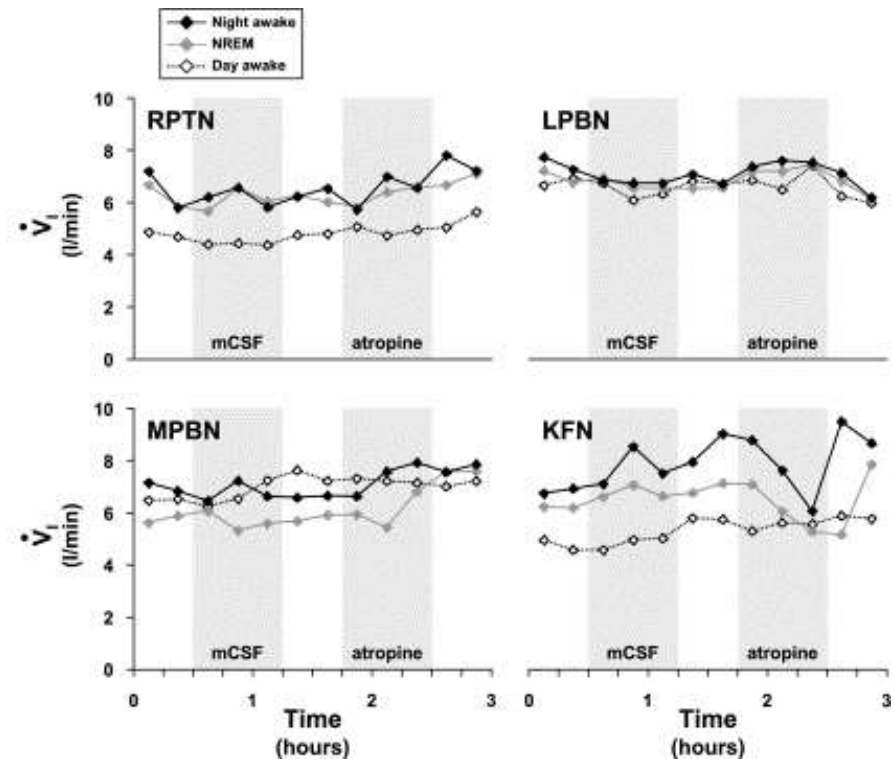

Fig. 3. Pulmonary ventilation (Vi) of 4 different goats during microdialysis (MD) of mock cerebrospinal fluid (MCSF) or atropine in studies during the day in the awake state and in studies at night during the awake and NREM sleep states. The MD was in either the rostral pontine tegmental nucleus (RPTN) or in the LPBN, MPBN, or KFN. Note the relatively stable Vi throughout the protocol for all goats except that for the nighttime studies in the KFN goat, Vi decreased during atropine MD in both the awake and NREM sleep states. Shaded boxes indicate periods of MD with either mCSF or atropine. 
NOT THE PUBLISHED VERSION; this is the author's final, peer-reviewed manuscript. The published version may be accessed by following the link in the citation at the bottom of the page.

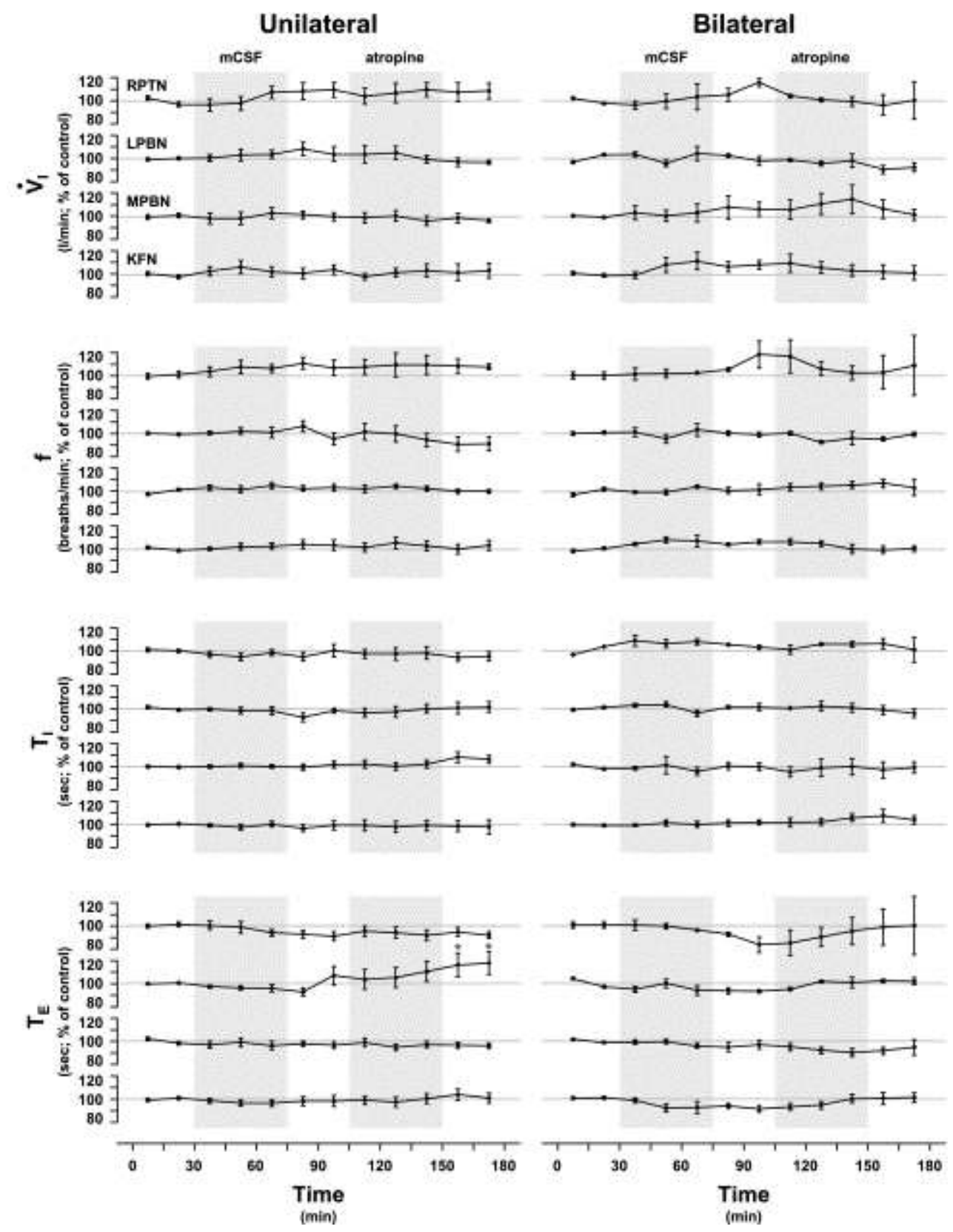

Fig. 4. Neither unilateral nor bilateral MD of either MCSF or atropine during daytime studies had any significant effect on ventilatory parameters, with the exception of an increase in expiratory time (Te) following unilateral MD of atropine into the LPBN $(n=$ $3)$. Data were obtained during MD in the RPTN $(n=3)$, MPBN $(n=4)$, or KFN $(n=6)$. $\mathrm{f}$, Breathing frequency; Ti, inspiratory time. Shaded boxes indicate periods of MD with either mCSF or atropine. ${ }^{*} P<0.05$, significant differences from control.

As also shown in Fig. 3, the exception to the stable Vi during the MD studies was during MD of atropine into the KFN at night, when Vi decreased during both the awake and NREM sleep states (Fig. 3). 
Indeed, unilateral MD of atropine into the KFN during nighttime studies significantly decreased Vi by $14 \%(P<0.001)$ during NREM sleep and also, although not significantly, by $12 \%(P=0.117)$ during wakefulness (Fig. 5). Bilateral MD of atropine significantly decreased Vi by $12 \%$ during wakefulness $(P<0.01)$ and also by $12 \%$ during NREM sleep, although this decrease was not statistically significant $(P=$ 0.127 ) (Fig. 5). Unilateral and bilateral decreases in Vi were due to decreases of $13 \%(P<0.001)$ and $12 \%(P<0.001)$ in $\mathrm{f}$, respectively, during wakefulness and NREM sleep (Fig. 5). In unilateral studies, $\mathrm{Ti}$ was increased by $18 \%(P<0.05)$ during NREM sleep and marginally by $13 \%(P=0.059)$ during wakefulness, whereas Te increased $19 \%(P$ $<0.001)$ during NREM sleep and $15 \%(P<0.001)$ during wakefulness (Fig. 5). In bilateral studies, $\mathrm{Ti}$ increased by $15 \%(P<0.05)$ during NREM sleep and $13 \%(P=0.21)$ during wakefulness, with Te increased by $23 \%(P<0.05)$ during NREM sleep and $19 \%(P<0.001)$ during wakefulness (Fig. 5). The effects of atropine MD were in many cases observed during recovery from MD, which probably reflects a relatively slow washout of atropine from the tissue. There were no significant changes in Vt (data not shown). Ventilatory data during REM sleep are not available because there was an insufficient amount for analysis.

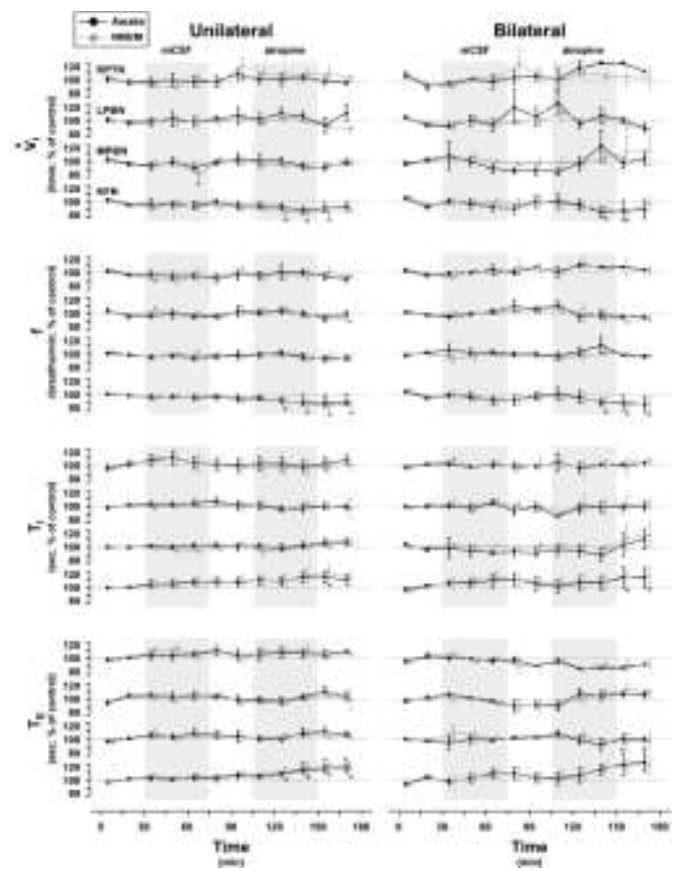

Fig. 5. Unilateral and bilateral MD of atropine during nighttime studies in KFN animals $(n=6)$ decreased $\mathrm{Vi}$ and $\mathrm{f}$ and increased $\mathrm{Ti}$ and Te during both awake and NREM sleep and permission has been granted for this version to appear in e-Publications@Marquette. American Physiological Society does not grant permission for this article to be further copied/distributed or hosted elsewhere without the express permission from American Physiological Society. 
states. There were no consistent and sustained changes in any variable during unilateral or bilateral MD of mCSF or atropine into the RPTN $(n=3)$, LPBN $(n=3)$, or MPBN $(n=4)$. Shaded boxes indicate periods of MD with either MCSF or atropine. $* P$ $<0.05$, significant differences from control.

With two exceptions, there were no consistent and sustained changes in any ventilatory variable during MD at night into the RPTN, LPBN, and MPBN (Fig. 5). One exception was during unilateral MD of mCSF at night, when Vi decreased $(P<0.05)$ in MPBN goats by $18 \%$ (Fig. 5). The second exception was in RPTN goats when unilateral MD at night increased $(P<0.05)$ Vi by $18 \%$ during recovery from MD of mCSF (Fig. 5). These changes probably reflect effects of MD per se.

There were no significant $(P<0.05)$ changes in the $\mathrm{CV}$ of any ventilatory variable during any study at all sites.

\section{Sleep.}

During the recovery period from bilateral MD of atropine into the KFN, the amount of NREM sleep (Fig. 6) was increased by $365 \%(P<0.01)$. This increase in NREM sleep was presumably due to a stabilization of sleep mechanisms, as evidenced by a $990 \%(P<0.001)$ increase in the average time per sleep epoch. During the recovery from unilateral MD of mCSF and atropine into the KFN, the time per sleep epoch was also significantly $(P<0.05)$ increased (Fig. 6). The percentage of time in NREM sleep was not significantly $(P<0.05)$ altered by MD of atropine into the RPTN, LPBN, or MPBN.

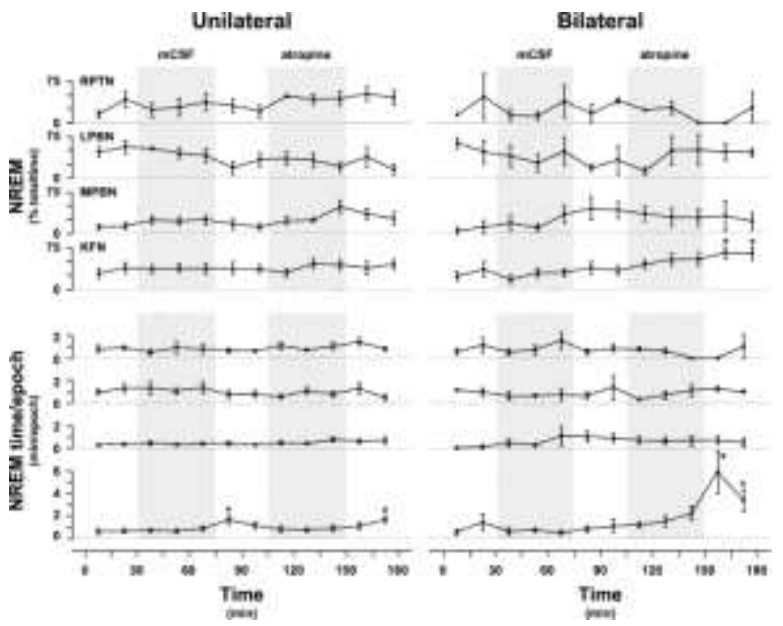

Fig. 6. During the recovery period from bilateral MD of atropine into the $\operatorname{KFN}(n=6)$, there was a significant $(P<0.05)$ increase in NREM sleep time and an increase the and permission has been granted for this version to appear in e-Publications@Marquette. American Physiological Society does not grant permission for this article to be further copied/distributed or hosted elsewhere without the express permission from American Physiological Society. 
duration of a NREM sleep epoch. During recovery from unilateral MD of either mCSF or atropine into the KFN, there was an increase in the duration of a NREM sleep epoch.

During MD of mCSF or atropine into the RPTN $(n=3)$, LPBN $(n=3)$, or MPBN $(n=4)$, there were no significant effects of NREM sleep time or duration of NREM epoch.

Shaded boxes indicate periods of MD with either mCSF or atropine. $* P<0.05$, significant differences from control.

\section{Respiratory muscle activity.}

Compared with control levels, unilateral and bilateral MD of atropine had no significant $(P<0.05)$ effect on the quantified integrated diaphragm, abdominal, or genioglossus (GG) (Fig. 7) muscle activity during daytime or nighttime studies. However, beginning during the MD of MCSF and persisting through MD of atropine, the CV for GG activity during the day was increased by $68 \%$ $(P<0.001)$ in unilateral studies and by $47 \%(P<0.001)$ in bilateral MD into the KFN (Fig. 8). There was no significant effect of MD on the CV for nighttime GG activity (Fig. 8). Furthermore, there was no significant effect on the variation of diaphragm or abdominal muscle activities. There were no data on GG activity for MD into the RPTN, because implantation of GG electrodes was added part way through the protocol and as such were not implanted in these initial animals.

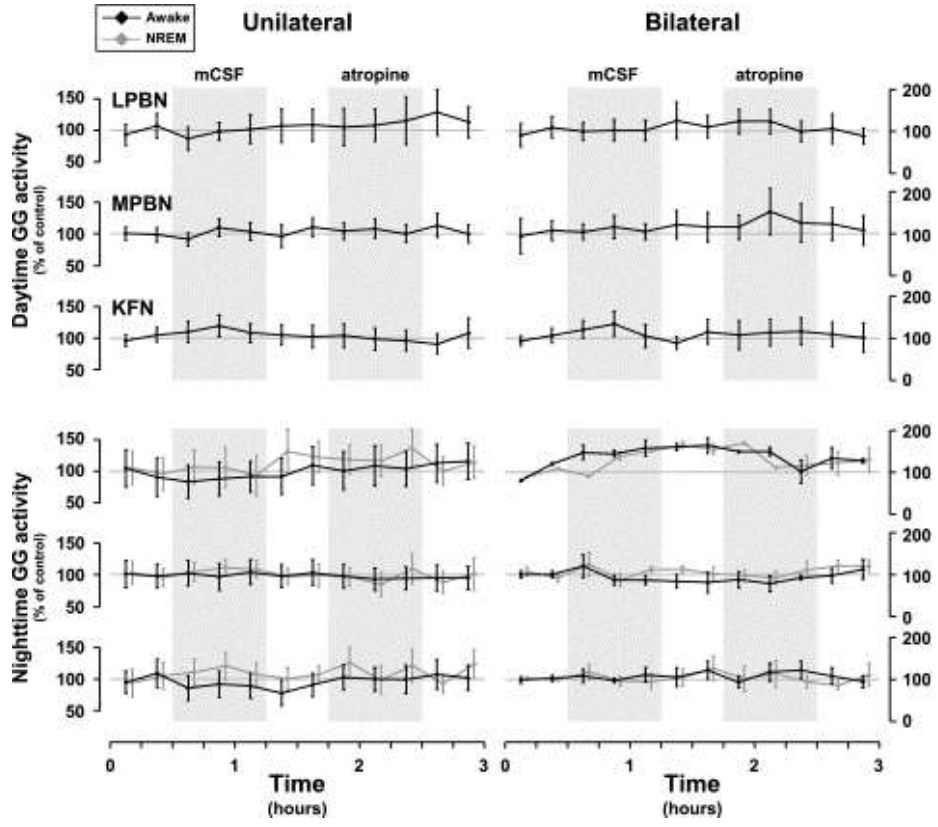

Fig. 7. There were no significant $(P>0.05)$ changes in the level of genioglossus (GG) muscle activity during MD of mCSF or atropine into the LPBN $(n=3), \operatorname{MPBN}(n=4)$, or KFN $(n=6)$ during daytime or nighttime studies. Shaded boxes indicate periods of MD with either $\mathrm{mCSF}$ or atropine. and permission has been granted for this version to appear in e-Publications@Marquette. American Physiological Society does not grant permission for this article to be further copied/distributed or hosted elsewhere without the express permission from American Physiological Society. 


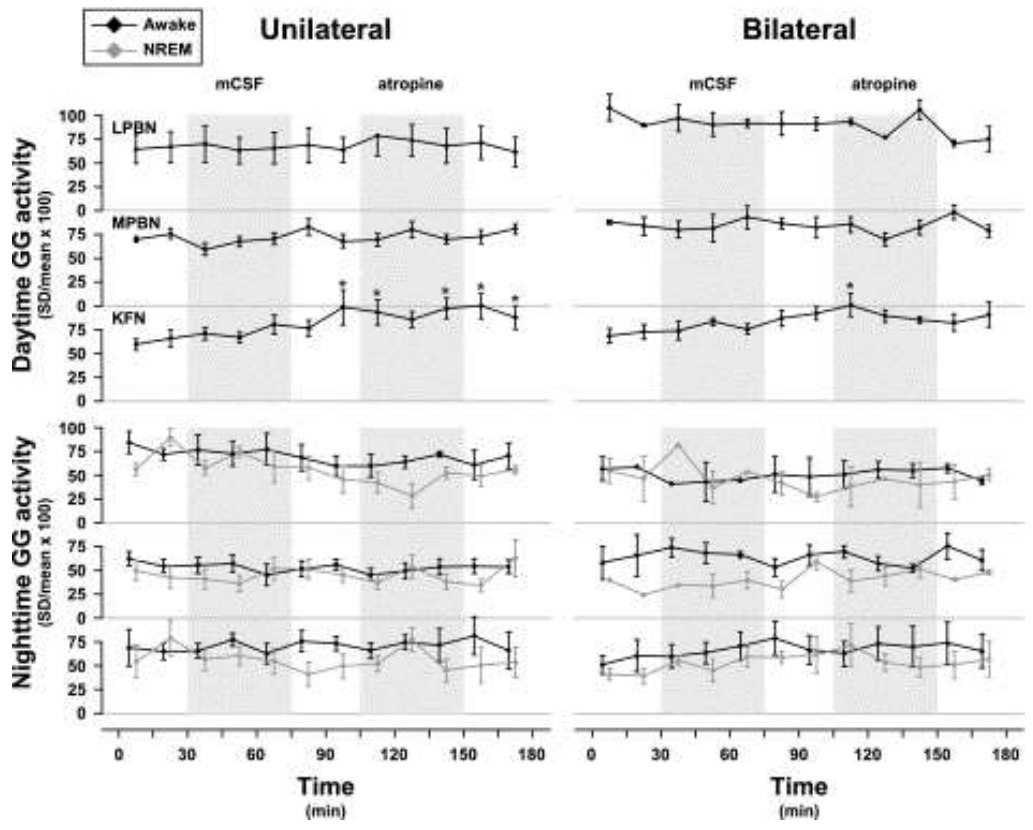

Fig. 8. The coefficient of variation $(C V ; S D /$ mean $\times 100)$ for daytime $G G$ muscle activity was increased during unilateral and bilateral MD of atropine into the $\mathrm{KFN}(n=$ $6)$. There was no significant effect on the CV of GG activity during MD into the KFN at night, and there were no significant $(P>0.05)$ effects with MD into the LPBN $(n=3)$ or MPBN $(n=4)$ during daytime or nighttime studies. Shaded boxes indicate periods of MD with either mCSF or atropine. $* P<0.05$, significant differences from control.

\section{Apneas and augmented breaths.}

MD into the RPTN during the day increased the mean number of apneas per total number of breaths compared with MD into the LPBN $(P<0.05)$, MPBN $(P<0.05)$, and KFN $(P<0.01)$ (data not shown). There were no other significant $(P<0.05)$ effects of MD on apneas or augmented breaths per total number of breaths during daytime or nighttime studies.

\section{Other physiological parameters.}

There were no significant consistent effects during the day or at night of unilateral or bilateral $\mathrm{MD}$ on $\mathrm{PacO}_{\mathrm{C}}, \mathrm{Pa}_{\mathrm{O} 2}, \mathrm{pH}_{\mathrm{a}}$, body temperature, $\mathrm{VO}_{2}, \mathrm{VCO}_{2}$, heart rate, or arterial blood pressure (data not shown). All values were within normal limits for goats. 
NOT THE PUBLISHED VERSION; this is the author's final, peer-reviewed manuscript. The published version may be accessed by following the link in the citation at the bottom of the page.

\section{Discussion}

\section{Summary.}

The major physiological changes observed in the present study are that unilateral and bilateral MD of atropine into the KFN at night decreased $\mathrm{Vi}$ and $\mathrm{f}$ and increased $\mathrm{Ti}$ and $\mathrm{Te}$ by $12-23 \%$ during both wakefulness and NREM sleep. Our primary hypothesis regarding statedependent effects of attenuating muscarinic receptor activity in the PRG was not validated.

\section{Limitations.}

One constraint of this study was our inability to unequivocally define the anatomic region affected by MD of atropine. The grouping of the goats was based on the distal-most tract created by the implanted cannula. The MD probe was inserted $2 \mathrm{~mm}$ beyond the tip of the cannula; thus the membrane for reverse MD was within the designated area. However, atropine may have diffused beyond respective target nuclei. Exactly how far, and to what extent, atropine diffused was dependent on numerous factors including rate of diffusion, metabolism, and clearance of atropine. The anatomical morphology and tissue reaction to the cannulas and/or probes may have caused a difference in diffusion at different PRG sites and/or differences between goats. However, the finding that bilateral MD of atropine at each PRG subnucleus uniformly decreased ACh and choline in the effluent fluid compared with MD of MCSF provides indirect evidence that atropine reached the tissue at each site (Table 1 ).

As shown in Fig. 2, the morphology of the LPBN and MPBN was quite different from that of the KFN. Compared with the KFN, the LPBN and MPBN are more widespread, larger in area, and contain more neurons. Accordingly, it was possible to only dialyze part of the LPBN and MPBN, whereas a relatively larger portion of the KFN was dialyzed when targeted; thus we cannot exclude the possibility of more prominent effects if atropine had been dialyzed into a larger portion of or in other parts of the LPBN and MPBN. Moreover, it is possible that the effective atropine concentration was not uniform at all PRG sites and during all periods of dialysis. It is conceivable that repeated 
insertion of the dialysis probe destroyed neurons and/or altered diffusion characteristics, thereby causing nonuniform delivery of atropine. We were unable to determine for each group the potential damage caused by dialysis, because after completion of the six dialysis studies, in all but one goat we studied the effects of injecting the neurotoxin ibotenic acid. In the single goat in which ibotenic acid was not injected, the number of neurons distal to the cannula were within the normal variation of the control goats. Thus we did not obtain any evidence that MD per se affected the tissue within the region dialyzed.

Another limitation of the present study is the small sample size in the LPBN, MPBN, and RTPN groups. As shown in Figs. 4 and 5, there were trends of changes induced by MD into these areas that might have been statistically significant if the number of goats was greater. Indeed, the power of some of the statistical analyses was less than 0.2 ; thus, for groups with a low number of goats, we cannot state with confidence whether changes indeed did or did not occur.

Because of these three limitations (uncertainty of diffusion distance and effective tissue atropine concentration, differences in morphology between PRG regions, and small sample size of 3 groups), it is inappropriate to conclude that there is a site-specific effect of atropine dialysis into the PRG. Our conclusion is that cholinergic modulation of KFN neurons contributes to the control of breathing during the night, but we cannot discount the possibility that cholinergic modulation of LPBN, MPBN, and RTPN neurons may also contribute to control of breathing.

\section{State-dependent changes in breathing.}

In most mammals, there is a decrease in breathing between wakefulness and NREM sleep. One postulated explanation for these changes is that the activity of serotonergic, adrenergic, and cholinergic neurons in the brain stem decreases between wakefulness and NREM sleep. ${ }^{6,27}$ If these are sources of excitatory neuromodulation of respiratory neurons, then the activity of respiratory neurons will be less during NREM sleep than during wakefulness. Indeed, it has been shown that the activity of PRG respiratory modulated neurons is less during NREM sleep than during wakefulness. ${ }^{16,30,33}$ Such reduced 
excitation could then contribute to the reduced breathing during NREM sleep compared with wakefulness.

If indeed cholinergic modulation is excitatory to PRG neurons and this excitatory effect is relatively greater during wakefulness than during NREM sleep, it seems appropriate to hypothesize that the effect of atropine attenuation of muscarinic activity in the PRG will be greater during wakefulness than during NREM sleep. However, we found that the effect of atropine MD into the KFN nearly equally reduced Vi during wakefulness and NREM sleep. In addition, during both states, the reduced Vi resulted from reduced $f$ secondary to increased Ti and Te. Accordingly, our data do not support the concept that lower KFN neuronal activity and lower Vi during NREM sleep are due to reduced excitatory cholinergic modulation of KFN neurons during NREM sleep relative to wakefulness.

The data from several studies have led to the conclusion that increased ACh release into the MPRF promotes REM sleep and depresses breathing through an effect on PRG respiratory neurons. ${ }^{21}$ We were unable to directly address this concept because of the minimal REM sleep in these goats. Nonetheless, our data do not provide support for the concept that there is a state-dependent effect of cholinergic modulation of breathing by PRG neurons.

\section{Day-night differences in effect of atropine.}

Except for a significant $(P<0.05)$ increase in Te during recovery from atropine MD into the LPBN, there were no other significant $(P<0.05)$ effects of atropine MD during the day; thus it is unlikely that cholinergic modulation of PRG neurons is a determinant of breathing during wakefulness during the day. The finding that atropine MD into the KFN depressed breathing during wakefulness at night but not during wakefulness during the day suggests that there is possibly a circadian component to cholinergic modulation of PRG neurons. The present study was not ideally designed to test for a circadian contribution to cholinergic modulation of breathing, because it would have required control of multiple variables, including feeding routine, standing vs. prone posture, behavior of chambermates, and visual cues associated with chronological time; thus our data do not establish a definitive circadian effect of cholinergic modulation. However, in and permission has been granted for this version to appear in e-Publications@Marquette. American Physiological Society does not grant permission for this article to be further copied/distributed or hosted elsewhere without the express permission from American Physiological Society. 
addition to sleep-dependent changes in neuromodulators, there also are documented circadian-dependent changes in neuromodulators. For example, serotonin levels in the pineal gland and the suprachiasmatic nucleus are lower in rats during the light cycle than during the dark cycle, and this difference appears to be controlled by circadian variation in adrenergic signaling. $4,12,25,37,38$ It is not known whether there are circadian variations in PRG cholinergic, adrenergic, and serotonin neuromodulation, but on the basis of our present findings, coupled with documented circadian variations in breathing, ${ }^{28,35}$ further studies are warranted on circadian variation of cholinergic modulation of PRG neurons.

\section{Cholinergic modulation of GG muscle activity.}

The tone of the pharyngeal GG muscle is reduced during NREM sleep, which reduces airway size and increases airway resistance, and in some humans this results in collapse of the airway (obstructive sleep apnea). The cause of these effects has not been established. Since there are projections from pontine cholinergic neurons ${ }^{32}$ to the hypoglossal nucleus, one potential contributing factor is altered cholinergic modulations of the motoneurons in the hypoglossal nucleus. Indeed, Kodama et al. ${ }^{19}$ found in decerebrate cats that microinjection of ACh into the rostral pons causes GG muscle atonia while simultaneously increasing both glycine and GABA release in the hypoglossal nucleus. Moreover, there are documented projections from the KFN to the hypoglossal nucleus, ${ }^{15,17,39}$ but the significance of these projections is unknown, leading Horner ${ }^{17}$ to conclude "it remains to be determined if modulation of central cholinergic activity importantly contributes to changes in GG activity across sleep-wake states." Accordingly, we sought to determine whether attenuation of PRG muscarinic receptor activity with MD of atropine would affect GG muscle activity. We did not obtain any significant evidence that either the magnitude or variability of GG muscle activity was altered by MD of atropine into any PRG subnucleus during wakefulness and NREM sleep. The stable and constant muscle activity occurred even though multiple ventilatory variables were affected and NREM sleep was promoted during atropine MD into the KFN. 
During the recovery from both unilateral and bilateral MD of mCSF into the KFN in daytime studies, variability in GG muscle activity began to increase, and it remained increased during and after MD of atropine. In addition, variability in GG muscle activity overall tended to be higher during the day than at night. Since pontine perturbations may affect a network with complex excitatory and inhibitory feedforward and feedback mechanisms that are postulated to contribute to the stabilization of breathing and respiratory muscle activity, ${ }^{13}$ it is not surprising that we found considerable variation in activity of the GG muscle. Disruption of this stabilizing role may contribute to sleep disordered breathing. However, the disruptions by MD per se and by MD of atropine during wakefulness and NREM sleep states in the present study did not cause profound destabilization characteristic of REM sleep.

\section{Effect of atropine MD on effluent ACh and choline and sleep.}

It seems that a logical consequence of attenuating muscarinic receptor activity in the PRG would be a compensatory increase in release of ACh. However, we found that MD of atropine resulted in a decrease in ACh and choline in the effluent dialysis fluid (Table 1). We are unable to explain this finding. However, the decrease in ACh may have contributed to two findings. First, the decreased ACh would seemingly have the same effect as attenuating muscarinic receptor activity with atropine. Indeed, the decrease in breathing during MD of atropine into the KFN could have been due to decreased ACh, rather than a direct effect of atropine on the muscarinic receptor. Second, a decrease in ACh also promotes NREM sleep; thus the increased amount of NREM sleep and increased in time per NREM sleep epoch during atropine MD into the KFN might be secondary to the decrease in ACh. 
NOT THE PUBLISHED VERSION; this is the author's final, peer-reviewed manuscript. The published version may be accessed by following the link in the citation at the bottom of the page.

\section{Grants}

This work was supported by the Department of Veterans Affairs and National Heart, Lung, and Blood Institute Grants HL25739 and HL007852.

\section{Disclosures}

No conflicts of interest, financial or otherwise, are declared by the author(s).

\section{Acknowledgments}

We especially thank Greg McQuestion and Heather Vernon for assistance in software development.

\section{References}

${ }^{1}$ Baghdoyan $\mathrm{H}$, Lydic R, Callaway C, Hobson J. The carbachol-induced enhancement of desynchronized sleep signs is dose dependent and antagonized by centrally administered atropine.

Neuropsychopharmacology 2: 67- 79, 1989

2 Baghdoyan H, Monaco A, Rodrigo-Angulo M, Assens F, McCarley R, Hobson J. Microinjection of neostigmine into the pontine reticular formation of cats enhances desynchronized sleep signs. J Pharmacol Exp Ther 231: $173-180,1984$

${ }^{3}$ Bagydoyan H, Rodrigo-Angulo M, McCarley R, Hobson J. Site-specific enhancement and suppression of desynchronized sleep signs following cholinergic stimulation of three brainstem regions. Brain Res 306: 3952,1984

${ }^{4}$ Barassin S, Raison S, Saboureau M, Bienvenu C, Maitre M, Malan A, Pevet P. Circadian tryptophan hydroxylase levels and serotonin release in the suprachiasmatic nucleus of the rat. Eur J Neurosci 15: 833- 840, 2002

${ }^{5}$ Bellingham MC, Berger AJ. Presynaptic depression of excitatory synaptic inputs to rat hypoglossal motoneurons by muscarinic $M 2$ receptors. J Neurophysiol 76: 3758- 3770, 1996

${ }^{6}$ Bellingham M, Ireland M. Contribution of cholinergic systems to statedependent modulation of respiratory control. Respir Physiol Neurobiol 131: 135- 144, 2002

7 Bertrand F, Hugelin A, Vibert J. A stereological model of pneumotaxic oscillator based on spatial and temporal distributions of neuronal bursts. J Neurophysiol 37: 91-107, 1974

${ }^{8}$ Bolser D, Poliacek I, Jakus J, Fuller D, Davenport P. Neurogenesis of cough, other airway defensive behaviors and breathing: A holarchical system? Respir Physiol Neurobiol 152: 255- 265, 2006 and permission has been granted for this version to appear in e-Publications@Marquette. American Physiological Society does not grant permission for this article to be further copied/distributed or hosted elsewhere without the express permission from American Physiological Society. 
NOT THE PUBLISHED VERSION; this is the author's final, peer-reviewed manuscript. The published version may be accessed by following the link in the citation at the bottom of the page.

${ }^{9}$ Burton M, Nouri K, Baichoo S, Samuels-Toyloy N, Kazemi H. Ventilatory output and acetylcholine: perturbations in release and muscarinic receptor activation. J Appl Physiol 77: 2275- 2284, 1994

${ }^{10}$ Cohen M. Switching of the respiratory phases and evoked phrenic responses produced by rostral pontine electrical stimulation. J Physiol 217: $133-158,1971$

${ }^{11}$ Cohen M, Shaw C. Role in the inspiratory off-switch of vagal inputs to rostral pontine inspiratory-modulated neurons. Respir Physiol Neurobiol 143: 127- 140, 2004

12 Czeisler C, Gooley J. Sleep and circadian rhythms in humans. Cold Spring Harb Symp Quant Biol 72: 579- 597, 2007

13 Dick TE, Shannon R, Lindsey BG, Nuding SC, Segers LS, Baekey DM, Morris $\mathrm{KF}$. Pontine respiratory-modulated activity before and after vagotomy in decerebrate cats. J Physiol 17: 4265- 4282, 2008

14 Douglas C, DeMarco G, Baghdoyan H, Lydic R. Pontine and basal forebrain cholinergic interaction: implications for sleep and breathing. Respir Physiol Neurobiol 143: 251- 262, 2004

15 Ezure K, Tanaka I. Distribution and medullary projection of respiratory neurons in the dorsolateral pons of the rat. Neuroscience 141: 10111023, 2006

${ }^{16}$ Gilbert K, Lydic R. Pontine cholinergic reticular mechanisms cause statedependent changes in the discharge of parabrachial neurons. Am J Physiol Regul Integr Comp Physiol 266: R136- R150, 1994

17 Herbert $H$, Moga M, Saper C. Connections of the parabrachial nucleus with the nucleus of the solitary tract and the medullary reticular formation in the rat. J Comp Neurol 293: 540- 580, 1990

18 Horner RL. Emerging principles, and neural substrates underlying tonic sleep-state-dependent influences on respiratory motor activity. Philos Trans R Soc Lond B Biol Sci 364: 2553- 2564, 2009

19 Kimura H, Kubin L, Davis R, Pack A. Cholinergic stimulation of the pons depresses respiration in decerebrate cats. J Appl Physiol 69: 22802289, 1990

${ }^{20}$ Kodama T, Lai Y, Siegel J. Changes in inhibitory amino acid linked to pontine-induced atonia: an in vivo microdialysis study. J Neurosci 23: 1548-1554, 2003

${ }^{21}$ Lee L, Friedman D, Lydic R. Respiratory nuclei share synaptic connectivity with pontine reticular regions regulating REM sleep. Am J Physiol Lung Cell Mol Physiol 268: L251- L262, 1995

22 Lydic R, Baghdoyan $\mathrm{H}$. Pedunculopontine stimulation alters respiration and increases $\mathrm{ACh}$ release in the pontine reticular formation. Am J Physiol Regul Integr Comp Physiol 264: R544- R554, 1993

${ }^{23}$ Lydic R, Baghdoyan $H$, Lorinc $Z$. Microdialysis of cats pons reveals enhanced acetylcholine release during state-dependent respiratory and permission has been granted for this version to appear in e-Publications@Marquette. American Physiological Society does not grant permission for this article to be further copied/distributed or hosted elsewhere without the express permission from American Physiological Society. 
NOT THE PUBLISHED VERSION; this is the author's final, peer-reviewed manuscript. The published version may be accessed by following the link in the citation at the bottom of the page.

depression. Am J Physiol Regul Integr Comp Physiol 261: R766- R770, 1991

${ }^{24}$ Lydic R, Orem J. Respiratory neurons of the pneumotaxic center during sleep and wakefulness. Neurosci Lett 15: 187- 192, 1979

25 Mallios $\mathrm{V}$, Lydic R, Baghdoyan $\mathrm{H}$. Muscarinic receptor subtypes are differentially distributed across brain stem respiratory nuclei. Am J Physiol Lung Cell Mol Physiol 268: L941- L949, 1995

26 Martinez D, Lenz Mdo C, Menna-Barreto L. Diagnosis of circadian rhythm sleep disorders. J Bras Pneumol 34: 173- 180, 2008

27 McGinty DJ, Harper RM. Dorsal raphe neurons: depression of firing during sleep in cats. Brain Res 101: 921- 933, 1976

28 Morales F, Engelhardt J, Soja P, Pereda A, Chase M. Motoneuron properties during motor inhibition produced by microinjection of carbachol into the pontine reticular formation of the decerebrate cat. J Neurophysiol 57: $1118-1129,1987$

29 Mortola JP. Correlations between the circadian patterns of body temperature, metabolism, and breathing in rats. Respir Physiol Neurobiol 155: 137- 146, 2007

30 Nuding SC, Segers LS, Shannon R, O'Connor R, Morris KF, Lindsey BG. Central and peripheral chemoreceptors evoke distinct responses in simultaneously recorded neurons of the raphe-pontomedullary respiratory network. Philos Trans R Soc Lond B Biol Sci 364: 25012516, 2009

31 Orem J, Osorio I, Brooks E, Dick T. Activity of respiratory neurons during NREM sleep. J Neurophysiol 54: 1144- 1156, 1985

32 Rukhadze I, Kubin L. Mesopontine cholinergic projections to the hypoglossal motor nucleus. Neurosci Lett 413: 121- 125, 2007

33 Segers LS, Nuding SC, Dick TE, Shannon R, Baekey DM, Solomon IC, Morris $\mathrm{KF}$, Lindsey BG. Functional connectivity in the pontomedullary respiratory network. J Neurophysiol 100: 1749- 1769, 2008

34 Sieck GC, Harper RM. Pneumotaxic area neuronal discharge during sleepwaking states in the cat. Exp Neurol 67: 79- 102, 1980

35 Shao XM, Feldman JL. Acetylcholine modulates respiratory pattern: effects mediated by $\mathrm{M} 2$-like receptors in preBötzinger complex inspiratory neurons. J Neurophysiol 83: 1243-1252, 2000

${ }^{36}$ Stephenson R, Mohan RM, Duffin J, Jarsky TM. Circadian rhythms in the chemoreflex control of breathing. Am J Physiol Regul Integr Comp Physiol 278: R282- R286, 2000

37 St John W. Medullary regions for neurogenesis of gasping: noued vital or noeuds vitals? J Appl Physiol 81: 1865- 1877, 1996

${ }^{38}$ Sun $\mathrm{H}$, Deng J, Liu T, Borjigin J. Circadian 5-HT production regulated by adrenergic signaling. Proc Natl Acad Sci USA 99: 4686- 4691, 2002 and permission has been granted for this version to appear in e-Publications@Marquette. American Physiological Society does not grant permission for this article to be further copied/distributed or hosted elsewhere without the express permission from American Physiological Society. 
NOT THE PUBLISHED VERSION; this is the author's final, peer-reviewed manuscript. The published version may be accessed by following the link in the citation at the bottom of the page.

39 Trulson ME, Crisp T, Trulson VM. Activity of serotonin-containing nucleus centralis superior (Raphe medianus) neurons in freely moving cats. Exp Brain Res 54: 33- 44, 1984

40 Yokota S, Tsumori T, Ono K, Yasui Y. Glutamatergic pathways from the Kölliker-Fuse nucleus to the phrenic nucleus in the rat. Brain Res 995: 118-130, 2004.

\section{Corresponding author.}

Address for reprint requests and other correspondence: H. V. Forster, 8701 Watertown Plank Road, Milwaukee, WI 53226 (e-mail: bforster@mcw.edu). 